\title{
Familial Experiences of Caring for Schizophrenia Patients during the Covid-19 Pandemic: A Qualitative Study
}

\section{Indriati Indriati', Wien Soelistyo Adi', Tuti Anggarawati², Yuni Astuti ${ }^{2}$ and Delisa Alfriani $^{1}$}

${ }^{1}$ Nursing Department of Health Polytechnic Semarang, Central Java, Indonesia

${ }^{2}$ Nursing Academy of Kesdam, Indonesia

\begin{abstract}
Introduction: Due to the Covid-19 pandemic, families are facing problems caring for and implementing Covid-19 health protocols when caring for schizophrenia patients. A lack of knowledge and behavior changes make it difficult for the families to care for the schizophrenia patients. This study aims to explore the familial experiences of caring schizophrenia patients during the Covid-19 pandemic.

Methods: A phenomenological qualitative design was undertaken as of November 2020. A total of 10 participants via the purposive sampling technique were recruited. The study was conducted in Semarang, Indonesia. We used semi-structured interviews to obtain the data and we used thematic content analysis to examine it.
\end{abstract}

Results: From the 10 participants, we got three themes, namely family fears, financial problems, and health treatment access. The themes were obtained from the families of the patients who care for them on a daily basis. During the Covid-19 pandemic, caring for schizophrenia patients has become more difficult and the cause of a lot of worry.

Conclusion: The families experienced several problems when caring for schizophrenia patients. The families experienced fear of the schizophrenia patients being infected by Covid-19, the families worried about whether or not the schizophrenia patients would experience a relapse and they felt stressed due to the news circulating. The families also had to spend more money to cover the cost of the patient's care and transportation, and the schizophrenia patients were rarely controlled because of the family's fears. This problem can be an issue for nurses who should strive to provide proper education and plan interventions for schizophrenia patients at the family level.

Cite this as: Indriati, I., Adi, W, S., Anggarawati, T., Astuti, Y., \& Alfriani, D. (2021). Familial Experiences of Caring for Schizophrenia Patients during the Covid-19 Pandemic: A Qualitative Study. Jurnal Ners, 16(1). 35-40. doi:http://dx.doi.org/10.20473/jn.v16i1.24130

\section{ARTICLE HISTORY}

Received: December 28, 2020

Accepted: February 22, 2021

family; experience; schizophrenia; COVID-19; pandemic

\section{CONTACT}

Delisa Alfriani

$\bowtie$ alfrianidelisa@gmail.com

$\risingdotseq$ Nursing Department of Health Java, Indonesia

\section{KEYWORDS} Polytechnic Semarang, Central

\section{INTRODUCTION}

The latest novel coronavirus disease (Covid-19) has become a problem around the world (Yang et al., 2020). Tens of thousands of people have died from this disease so far (Chakraborty \& Maity, 2020). The transmission of Covid-19 from one person to another can be through droplets in the air, contaminated surfaces, fecal-oral or through contact with human waste. The prevention of Covid-19 transmission can be done by implementing strict health protocols 
19 could be a stressor for schizophrenia patients that may cause emotional problems. According to the WHO, (2020), a pandemic causes stress to various layers of society. Previous studies related to previous pandemics such as severe acute respiratory syndrome (SARS) have shown there to be a negative impact on the mental health of sufferers. Research among SARS survivors showed that in the medium and long-term (41-65\%), the survivors experienced various kinds of psychological disorder (Maunder, 2009). In addition, a study conducted in Hong Kong showed that the psychological problems of SARS survivors did not diminish within one year of the incident and that $64 \%$ of survivors had the potential to experience psychiatric disorders (Lee, 2007).

The Covid-19 pandemic has caused stressors to arise. Families must improve their ability to adapt to the Covid-19 pandemic so then they are able to treat the schizophrenia patients optimally (Brailovskaia \& Margraf, 2020). Due to the Covid-19 pandemic, caring for patients should reflect their health and security needs. Their relatedness needs consist mainly of their interpersonal needs, humanistic concern needs, and family needs. Furthermore, their growth needs are mainly reflected as a strong need for knowledge. Existence needs are the main needs during an epidemic, with the health and security needs influencing each other. Humanistic concern needs are the most important of the relatedness needs (Yin \& Zeng, 2020). The government's efforts to overcome the mental and psychosocial health impacts due to the Covid-19 pandemic have been summarized by the composition of a guidebook for mental and psychosocial support and how to engage in mental and psychosocial support for the volunteers (Kemenkes, 2020).

A previous study showed that the family description of caring for schizophrenia patients includes the family knowledge of the disease, any treatment efforts, the family functions, social support (Attepe Özden \& Tuncay, 2018), the family acceptance regarding readiness to care (Diorarta \& Pasaribu, 2018), any emotional and physical burdens (Reknoningsih et al., 2015), support needs and changed perspectives (Attepe Özden \& Tuncay, 2018; Ntsayagae et al., 2019). The experience of the families when caring for schizophrenia patients feels different in the Covid-19 pandemic. Families must care for the patients while adjusting to the health protocols on Covid-19. It is not easy for the families to do this. Thus, the researchers conducted this research with the aim of exploring the family experience of caring for schizophrenia patients during the Covid-19 pandemic.

\section{MATERIALS AND METHODS}

This research used a qualitative study with a phenomenological approach. In this study, the sampling technique used was purposive sampling. To get the participants, the researcher collected data on the number of schizophrenia patients in the study location and found 16 schizophrenic patients in total. The door-to-door technique to get participants according to the inclusion criteria was carried out. One of the family members who was responsible for the patient was selected as the participant. The participants were selected on the condition that they were able to read and write, that they live with the schizophrenia patients, that they had cared for the schizophrenia patients for approximately two years, that they were aged 16 - 70 years old, and that they were able to communicate in either Indonesian or Javanese. We got 10 participants in total who matched the study inclusion criteria. The identity of each participant was protected using a code known only to the researcher. In addition, the research data in the form of recordings, field notes, and other notes were kept confidential by the researchers and have only been used for research purposes.

The study was conducted in November 2020 in the public health center (PHC) in Semarang, Indonesia. We used semi-structured interviews to obtain the data. The interview guidelines were developed by the researchers. The interview guideline component consisted of the problems that arise while caring for schizophrenic patients during the Covid-19 pandemic such as family anxiety, how the family copes with problems, and the support system that the family needs. Each question set began with an open-ended question. The interview process was conducted in the homes of the participants and was only attended by the participants and researchers. This was done in order to get a detailed description of the information. As this took place during the Covid-19 pandemic, the researchers adhered to the health protocols by wearing masks, by not touching participants, and by maintaining a distance from the participants during the interviews. The interviews were conducted for 30 until 45 minutes. The interview process was carried out twice in order to get as complete of a set of information as possible. Data triangulation was applied to the interview design. The researchers used the methodological triangulation approach and researcher triangulation. The triangulation method involves using more than one data collection technique to obtain the same data, such as using audio recorders and observation techniques tied into the field notes.

The transcription process was carried out after completing the interview. When saturation was reached and no new information was obtained, the data retrieval process was stopped. The data transcripts and analyzes were returned to the participants for cross-checking. The researchers also engaged in consultations with experts in qualitative research and mental disorders to obtain the most accurate data. The researchers kept the raw study data non-anonymous for two months until the analysis and research processes were complete. The researcher submitted an application to the Health Commission Ethics Services for permission to delete the raw research data and it was approved. 
The analysis process was carried out using a thematic analysis approach (Braun et al., 2006). The researchers were assisted by NVIVO software version 12 regarding the coding, data management and quotations gained from the participants.

The ethical principles, referring to the National Guidelines for Health Research Ethics in 2004, consist of three principles, namely respect for persons, beneficence, and justice. This study received approval from the Health Research Ethics Committee of the Health Polytechnic of the Ministry of Health in Semarang on 4 November 2020, number 276/EA/KEPK/2020.

\section{RESULTS}

In reference to the 10 participants in this study, the majority of the respondents were aged 30 - 45 years old with the majority of them having an education level of senior high school completion. The gender proportion of the participants in this study was equal between male and female, and the majority were housewives. The majority of the participants had treated the schizophrenia patients for 1 - 10 years.

In our study, we determined there to be three themes, namely family fears, financial problems, and health treatment access. The details for each theme have been described as follows.

\section{Theme 1: Family Fears}

We found that as many as 7 participants (P1, P3, P4, P5, P7, P8 and P9) in this study were addressing the fears of the family as a whole and the schizophrenia patients in particular being infected by Covid-19. This theme was identified through 4 sub-themes, namely death, non-compliance, and infectiousness. The participants expressed a fear of death caused by Covid-19. The participants saw a lot of news about deaths caused by Covid-19, so the participants felt afraid if their families and patients died from Covid19. This is expressed in the following sentence:

"On television, there is a lot of news about the huge number of deaths due to COVID-19. I'm afraid... I'm afraid if my family and this patient will also infected by COVID-19. Can die from the disease. COVID-19 is not visible, so you don't know, and anyone can get out of COVID-19..." (P1)

Furthermore, the non-compliance of the patients concerning using masks and washing their hands made families afraid of the patients being more easily infected by Covid-19. This is expressed in the following sentence:

"You must know that schizophrenia patients have to be told, sometimes obey, sometimes not... sometimes they want to wear a mask, sometimes they take it off because they can't breathe. So it's hard to be told to use a mask. Wash hands before eating. This patient is very difficult to be told to comply with health protocols ..." (P7)

The participants mentioned that the Covid-19 disease is very infectious. 'So I have to be careful. I, my family, and patients do not get infected.' The participants also said that in order to reduce their fear, they listened to less news on Covid-19, limited the patients from interacting with other people, and advised the patients to wash their hands regularly. This is expressed in the following sentence:

"I'm also afraid if I catch COVID-19. Very dangerous. I usually tell patients to wash their hands frequently using running water in the bathroom. I also rarely watch news about COVID-19, so I'm not too scared." (P9)

\section{Theme 2: Financial Problems}

In this study, 6 participants (P1, P2, P3, P5, P9 and $\mathrm{P} 10)$ revealed that caring for schizophrenia patients during Covid-19 had resulted in additional costs such as the cost of purchasing masks, hand sanitizer and safe transportation. While treating the schizophrenia patient, the family had to spend extra money while their income decreased. This is because several family members were fired from work. This theme was identified through the sub-themes of health protocol costs and daily living costs.

The participants complained about the additional costs of purchasing masks and hand sanitizer on a regular basis. At the start of the pandemic, masks and hand sanitizer were very expensive. However, the participants still bought these items to prevent themselves from being infected with Covid-19. This is expressed in the following sentence:

"The price of masks is very expensive. But we still have to buy that. So that I, my family, and the patient are not infected with COVID-19. It's okay for me to pay extra, as long as my family is not infected with COVID-19. But... if this continues, I can't. Because income has decreased..." (P1)

In addition, the participants also complained about the increase in the cost of basic necessities such as vegetables, rice, and transportation costs used to bring the patients to the hospital. The participants choose to save money by reducing any excess expenditure. Apart from that, the assistance from the local government was also very helpful. This is expressed in the following sentence:

"...What can we do? All the prices of basic necessities also go up. Vegetables, large, and others also went up. The transportation costs for treating my child to the hospital also went up. All prices have gone up. But I have to be frugal, not be wasteful, I have to be smart in managing expenses. The local government also provided assistance. Just lighten up ..." (P9)

\section{Theme 3: Health Treatment Access}

There were 7 participants (P1, P2, P4, P5, P6, P7 and P10) who said that while caring for schizophrenia patients during the Covid-19 period, they felt that the procedures they had to go through to get health treatment or control had to go through many procedures, such as checking their temperature, screening, and rapid testing. In addition, during a pandemic, it is rare for the patients to go to the hospital. The theme was obtained through 3 subthemes, namely examination procedures, rarely in 
control, and persuading the patients to control themselves.

The participants said that in order to be able to establish control at the hospital, the participants and patients must go through strict health examination procedures such as screening, temperature checks and proving that they are free of Covid-19 through rapid tests. The participants felt that this made ensuring control in the hospital take longer and be more difficult. This is expressed in the following sentence:

"To be honest, sir ... during the COVID-19 pandemic, there were more procedures for examination. My brother (patient) must wear a mask. It is very difficult for my sister to be asked to wear a mask. My brother also had to be examined before he was admitted to the hospital, using a thermometer like that shot. My brother got scared. Not to mention, first if you want to check you have to bring a rapidtest result. Have to spend more money. Yes, I find it more difficult during this pandemic..." (P2)

We found that during a pandemic, the patients are rarely under control and were often admitted to the hospital. This is because the procedure is long, and the participants were afraid that the patient can become infected in the hospital. The family themselves came to the hospital to get the medicine. This is expressed in the following sentence:

"I rarely took my son (patient) during this pandemic for treatment sir... I am afraid that my son will be infected by COVID-19. So, I myself came to the hospital to get the medicine. My son stays at home." (P5)

During the Covid-19 pandemic, the participants said that getting the patients to the hospital had become more difficult. One patient said that he was afraid that he would catch Covid-19 in the hospital.

"My brother is very difficult to control to the hospital. Especially during the COVID-19 pandemic. He (patient) is afraid of being infected with COVID19. I'm scared too. Then, I usually chat with the doctor via WhatsApp for the consul regarding my brother's condition." (P7)

\section{DISCUSSION}

Covid-19 places an emotional burden on the families caring for schizophrenia patients. The emotional problems experienced by the families include an increased fear of death due to Covid-19, patient noncompliance with the health protocols, and the risk of transmission of Covid-19. Previous research has shown that Covid-19 induces fear in everyone (Fitzpatrick et al., 2020; Mertens et al., 2020). The previous research is in accordance with this research. We learned that the participants experienced a fear of being infected with Covid-19 which could result in the death of their family members. Providing appropriate information can reduce participant fear excessively.

Patients with schizophrenia have the potential to not comply with the Covid-19 prevention health protocols because of their impaired cognition and consideration. According to (Stuart, 2013) schizophrenia is characterized by changes in tension, cognition, sensation, personality, lifestyle, attention, willpower, emotions, thought processes, psychomotor, memory, association, and the consideration of others. Patients with schizophrenia are less aware of the external environment that is currently being hit by the Covid-19 pandemic and they are less able to make choices about wearing masks, maintaining distance, and washing their hands frequently to prevent Covid-19 transmission (London, 2020; Szczesniak et al., 2020). This situation causes the focus of the family on the patients with schizophrenia to increase, including accompanying them and ensuring that the patients do not contract and transmit Covid-19 by repeatedly advising the patients to comply with the health protocols.

In this study, we also found that during Covid-19, the participating families were very vulnerable to experiencing financial problems. During Covid-19, families need extra expenses to purchase masks, transportation, and daily necessities. Previous research has shown that Covid-19 causes financial problems that have an impact on meeting their needs (Adekoya \& Oliyide, 2020; Wolfe \& Patel, 2021). Not only that, to protect themselves from Covid-19, the families must buy masks at a higher price (Garber, 2020). Financial disruption greatly impacts the care of schizophrenia patients. The treatment required includes providing their basic necessities such as food and drink, using personal protective equipment, and the need for a consultation at the hospital. The LargeScale Social Restrictions Regulation ultimately limits human activities in terms of working hours, the use of public transportation and the enforcement of trade restriction regulations. Collectively, these have a major impact on the business sector. People do not leave their homes due to the fear of contracting Covid19 , so the demand for offline products has decreased dramatically. In contrast, the online demand has increased sharply. According to Kiril Mankovski, in times like these, the majority of people tend to choose cashless transactions to maintain their health (Mihaela Rus, Mihaela Luminița Sandu, 2020).

During Covid-19, the participants faced difficulty getting access to and seen by the health services including more complicated health care procedures. This has an impact on the patients seeking control and treatment in the hospital. Previous research has shown that Covid-19 reduces the number of visits by schizophrenia patients for control at the hospital (Gonçalves-Pinho et al., 2020; Moreno et al., 2020). For this reason, persuasion techniques can be used by the families to make bringing the schizophrenia patients to the hospital easier (Rus-Calafell et al., 2015). Furthermore, during the Covid-19 pandemic, the participants came to the hospital to get the patient's medicine. This is done to keep the patient's condition stable during the Covid-19 pandemic.

This study provides an overview of the experiences of the families treating schizophrenia patients. However, this study is still limited in terms 
of the number of participants. In the future, studies with a larger number of participants can provide a more detailed picture of the family experiences when treating schizophrenia patients.

\section{CONCLUSION}

The Covid-19 pandemic puts an emotional burden on the families in caring for schizophrenia patients. Fear of being infected with Covid-19, which can result in death, becomes an emotional burden for the participants. Not only that, the Covid-19 pandemic can result in financial problems that in turn can have an impact on patient care. This causes the basic needs and care of the schizophrenia patients to be disrupted. Furthermore, due to the limitations in terms of access to the health services, the patients still have to receive good care and their medication regularly. For this reason, families must look for other alternatives to treat the schizophrenia patients by making savings, taking drugs on behalf of the family and online consultation with doctors. Providing the correct information can reduce the level of participant fear regarding Covid-19. Furthermore, the results of this study can be used as basic information when making policies at the level of the local government. It can also allow nurses to determine the appropriate nursing interventions to use through education. Further research with different approaches and designs is needed for the development of the information.

\section{REFERENCES}

Adekoya, O. B., \& Oliyide, J. A. (2020). How COVID-19 drives connectedness among commodity and financial markets: Evidence from TVP-VAR and causality-in-quantiles techniques. Resources Policy, 101898. https://doi.org/10.1016/j.resourpol.2020.10189 8

Attepe Özden, S., \& Tuncay, T. (2018). The experiences of Turkish families caring for individuals with Schizophrenia: A qualitative inquiry. International Journal of Social Psychiatry, 64(5), 497-505. https://doi.org/10.1177/0020764018779090

Brailovskaia, J., \& Margraf, J. (2020). Predicting adaptive and maladaptive responses to the Coronavirus (COVID-19) outbreak: A prospective longitudinal study. International Journal of Clinical and Health Psychology, 20(3), 183-191. https://doi.org/10.1016/j.ijchp.2020.06.002

Braun, V., Clarke, V., Braun, V., \& Clarke, V. (2006). Applied Qualitative Research in Psychology. Applied Qualitative Research in Psychology, 3(2), 77-101. https://doi.org/10.1057/978-1-13735913-1

Chakraborty, I., \& Maity, P. (2020). COVID-19 outbreak: Migration, effects on society, global environment and prevention. Science of the Total Environment,

728 ,

138882. https://doi.org/10.1016/j.scitotenv.2020.13888 2

Diorarta, R., \& Pasaribu, J. (2018). The Experiences of Family in Caring Schizophrenic Patients With Violent Behavior. Jurnal Keperawatan, 10(2), 106113.

Fitzpatrick, K. M., Drawve, G., \& Harris, C. (2020). Facing new fears during the COVID-19 pandemic: The State of America's mental health. Journal of Anxiety Disorders, 75, 102291. https://doi.org/10.1016/j.janxdis.2020.102291

Garber, A. (2020). Analysis: Coronavirus Spike Most Surgical Mask, Sanitizer Proces at Least 505 on Amazon.

Gonçalves-Pinho, M., Mota, P., Ribeiro, J., Macedo, S., \& Freitas, A. (2020). The Impact of COVID-19 Pandemic on Psychiatric Emergency Department Visits - A Descriptive Study. Psychiatric Quarterly. https://doi.org/10.1007/s11126-020-09837-z

Kemenkes. (2020). Direktorat Jenderal Pencegahan dan Pengendalian Penyakit Kementerian Kesehatan RI Tahun 2020. Germas, 1-64.

Kementrian Kesehatan Republik Indonesia. (2020). Corona virus disease 2019 Pedoman Pembatasan Sosial Berskala Besar dalam Rangka Percepatan Penanganan Corona Virus Disease 2019 (COVID19). In Menteri Kesehatan Republik Indonesia: Vol. Nomor 9.

London, S. (2020). COVID-19, Autonomy, and the Inpatient Psychiatric Unit. Academic Psychiatry, 44(6), 671-672. https://doi.org/10.1007/s40596-020-01314-w

Maunder, R. G. (2009). Was SARS a mental health catastrophe? General Hospital Psychiatry, 31(4), 316-317.

https://doi.org/10.1016/j.genhosppsych.2009.0 4.004

Mertens, G., Gerritsen, L., Duijndam, S., Salemink, E., \& Engelhard, I. M. (2020). Fear of the coronavirus (COVID-19): Predictors in an online study conducted in March 2020. Journal of Anxiety Disorders, 74, 102258. https://doi.org/10.1016/j.janxdis.2020.102258

Mihaela Rus, Mihaela Luminița Sandu, T. T. (2020). A new decade for social changes. Technium:Social Science Journal, 6(6), 69-87.

Moreno, C., Wykes, T., Galderisi, S., Nordentoft, M., Crossley, N., Jones, N., Cannon, M., Correll, C. U., Byrne, L., Carr, S., Chen, E. Y. H., Gorwood, P., Johnson, S., Kärkkäinen, H., Krystal, J. H., Lee, J., Lieberman, J., López-Jaramillo, C., Männikkö, M., ... Arango, C. (2020). How mental health care should change as a consequence of the COVID-19 pandemic. The Lancet Psychiatry, 7(9), 813-824. https://doi.org/10.1016/S2215-0366(20)303072

Ntsayagae, E. I., Poggenpoel, M., \& Myburgh, C. (2019). Experiences of family caregivers of persons living with mental illness: A meta-synthesis. Curationis, 42(1), 1900. https://doi.org/10.4102/curationis.v42i1.1900 
Reknoningsih, W., Daulima, N. H. C., \& Putri, Y. S. E. (2015). Pengalaman Keluarga dalam Merawat Pasien Pascapasung. Jurnal Keperawatan Indonesia, 18(3), 171-180. https://doi.org/10.7454/jki.v18i3.421

Rus-Calafell, M., Caqueo-Urízar, A., Urzúa, A., Escudero, J., \& Gutiérrez-Maldonado, J. (2015). The role of family therapy in the management of\&amp;nbsp;schizophrenia: challenges and solutions. Neuropsychiatric Disease and Treatment, 145 https://doi.org/10.2147/NDT.S51331

Sang Min Lee, Crystal R. Baker, Seong Ho Cho, Danette E. Heckathorn, Michael W. Holland, Rebecca A. Newgent, Nick T. Ogle, Michael L. Powell, James J. Quinn, S. L. W. \& K. Y. (2007). Development and Initial Psychometrics of the Counselor Burnout Inventory, Measurement and Evaluation in Counseling and Development. https://doi.org/10.1080/07481756.2007.11909 811

Stuart, G. (2013). Principles and Practice of psychiatric Nursing. Mosby, Inc.

Szczesniak, D., Ciulkowicz, M., Maciaszek, J., Misiak, B., Luc, D., Wieczorek, T., Witecka, K.-F., \& Rymaszewska, J. (2020). Psychopathological responses and face mask restrictions during the
COVID-19 outbreak: Results from a nationwide survey. Brain, Behavior, and Immunity, 87, 161162. https://doi.org/10.1016/j.bbi.2020.05.027

WHO. (2020). Physical Health and Psychosocial Considerations During the Coronavirus Disease 2019 Outbreak. Psychosomatics, 61(6), 851-852. https://doi.org/10.1016/j.psym.2020.07.005

Wolfe, M. T., \& Patel, P. C. (2021). Everybody hurts: Self-employment, financial concerns, mental distress, and well-being during COVID-19. Journal of Business Venturing Insights, 15, e00231. https://doi.org/10.1016/j.jbvi.2021.e00231

Yang, J., Zheng, Y., Gou, X., Pu, K., Chen, Z., Guo, Q., Ji, R., Wang, H., Wang, Y., \& Zhou, Y. (2020). Prevalence of comorbidities and its effects in coronavirus disease 2019 patients: A systematic review and meta-analysis. International Journal of Infectious Diseases, 94, 91-95. https://doi.org/10.1016/j.ijid.2020.03.017

Yin, X., \& Zeng, L. (2020). A study on the psychological needs of nurses caring for patients with coronavirus disease 2019 from the perspective of the existence, relatedness, and growth theory. International Journal of Nursing Sciences, 7(2), 157-160.

https://doi.org/10.1016/j.ijnss.2020.04.002 